\title{
NOTÍCIAS-CRIME NO MINISTÉRIO PÚBLICO FEDERAL DE GURUPI-TO: CARACTERÍSTICAS E REPERCUSSÃO SOCIAL
}

\section{CRIME NEWS IN THE FEDERAL PUBLIC MINISTRY OF GURUPI-TO: CHARACTERISTICS AND SOCIAL IMPLICATIONS}

\author{
Liane Poleto Marin 1 \\ Fábio Araújo Silva ${ }^{2}$
}

\section{RESUMO}

A Constituição Federal de 1988 do Brasil, entre outras previsões para o Estado Democrático de Direito, instituiu o Ministério Público e diversas formas de participação popular. Logo, criaram-se vários instrumentos e espaços para o ativismo civil e o Ministério Público Federal (MPF) tornou-se uma espécie de "ouvidoria" da sociedade brasileira. Sob essa ótica, indaga-se sobre as providências de autuação e o resultado prático das notícias criminais da população e da Administração Pública no âmbito do MPF. A adequada atuação das instituições públicas afeta diretamente a confiança do povo em relação ao Estado e, por consequência, o seu espírito participativo e colaborativo. Considerando que para o bom funcionamento da máquina estatal é preciso aliar a prestação de serviços à colaboração popular, se analisa o papel da Procuradoria da República em Gurupi-TO, de janeiro de 2013 a outubro de 2018, como se originam as notícias-crime e como $o$ ato do noticiante repercute na sociedade por fruto da atuação do órgão ministerial no exercício de seu poder investigador. $\mathrm{Na}$ apuração se determinam vistorias nos locais de crime, prestam informações os envolvidos e pode o próprio representante contribuir com o feito a qualquer tempo, sendo cientificado de toda medida com relevância. Para fundamentar essa pesquisa descritiva, a coleta de dados se deu principalmente pelas leis, portarias, Sistema Aptus e Sistema Único Digital do MPF. Como resultado, no período indicado ofertou a Procuradoria cerca de 61 ações penais na Vara da Justiça Federal em Gurupi-TO, graças à participação popular sul-tocantinense.

PALAVRAS-CHAVE: Ministério Público Federal. Notícia-crime. Repercussão Social.

\footnotetext{
1 Pós-Graduanda em Direito Público pelo Instituto de Ensino Pesquisa e Extensão - IEP/Tocantins; Bacharel em Direito pela Universidade de Gurupi - UNIRG. E-mail: liane.poleto.marin@gmail.com. ORCID no 0000-0002-9635-3251.

${ }^{2}$ Mestre em Produção Vegetal pela UFT; Pós-Graduado em Direito Tributário pela Unisul; Pós-Graduado em Ciências Penais pela Universidade Anhanguera; Pós-Graduado em Direito Público pela Universidade Anhanguera; Graduado em Direito pela Universidade de Gurupi - UNIRG. E-mail: fabiosilva2020@yahoo.com.br. ORCID no 0000-0002-5190-8700.
} 


\begin{abstract}
The Federal Constitution of 1988, among other predictions for the Democratic State of Law, instituted the Public Ministry and various forms of popular participation. Soon, several instruments and spaces for civil activism were created and the Federal Public Ministry became a kind of "ombudsman" of Brazilian society. From this view, it is inquired about measures of assessment and practical result of the criminal news of the population and the Public Administration within the Ministry. The performance of public institutions directly affects the people's trust in relation to the state and, consequently, their participatory and collaborative spirit. Considering that for the proper functioning of the state machine, it is necessary to combine the provision of services with popular collaboration, the role of the Office of the Attorney-General in Gurupi-TO, from January 2013 to October 2018, is analyzed as the origin of crime news and as the communication reverberates in society as a result of the action of the Ministry in the exercise of its investigative power. In investigation, they order crime scene inspections, those involved give testimonies and the representative himself can contribute to the crime at any time, being informed of any relevant measures. To support this descriptive research, data collection was mainly by laws, ordinances, Aptus System and Digital Unified System of Public Ministry, As a result, in the indicated period, the Attorney General's office offered about 61 criminal actions in the Federal Court of Justice in Gurupi-TO, thanks to the popular participation of the people of South Tocantins.
\end{abstract}

KEYWORDS: Federal Public Ministry. Crime News. Social Repercussion.

\title{
1 INTRODUÇÃO
}

A Constituição Federal Brasileira instituiu, em seu art. 1ํ, parágrafo único, que todo poder emana do povo (BRASIL, 1988), característica de repúblicas democráticas. Assim, a reação popular quando da ciência de irregularidades, ilícitos e violações dos direitos exigíveis em um Estado Democrático de Direito, de forma geral, é a de explorar o poder de sua voz, comunicando-os às autoridades, um ato de cidadania.

A justiça, como um valor urgente e contido na raiz dos valores sociais, acompanha as ideias de segurança e estabilidade jurídica. Diz-se que o valor justiça é um conceito objetivo e a finalidade da própria lei. Dessa feita, é possível mensurar a íntima ligação entre a confiança nas instituições públicas, uma percepção subjetiva, e a justiça social, até certo ponto, materialmente observável.

Ocorre que paira, nos últimos anos, um sentimento de impotência nos brasileiros, o que levou a um notável fraquejo de confiança na relação Estado-população. Pesquisas revelaram que o Brasil enfrenta um período de descrença generalizada em relação às instituições públicas (HERÉDIA, 2017, on-line), com uma taxa de pelo menos 
$62 \%$ de desconfiança, em estimativa do criterioso estudo global Edelman Trust Barometer (JORDÃO, 2017, on-line).

No entanto, ainda assim os cidadãos recorrem às ouvidorias, salas de atendimento ao cidadão e ferramentas do gênero disponibilizadas pelos órgãos públicos, na tentativa de verem satisfeita a tutela de seus direitos. Considerando o papel do Ministério Público Federal (MPF) perante a sociedade, na qualidade de instituição em defesa dos direitos sociais e individuais indisponíveis, da ordem jurídica e do regime democrático, concebida no Capítulo IV da Constituição de 1988, o MPF tornou-se uma espécie de "ouvidoria" da sociedade.

Assim, indaga-se sobre a atuação do Ministério Público Federal em relação às notícias-crime, na condição de fiscal da lei e dos direitos individuais e coletivos, regido pelo Princípio da Indisponibilidade. Em prol da defesa do interesse público federal descrito nos incisos do art. 109 da Carta Maior (BRASIL, 1988), foi inaugurada em 2013 a Procuradoria da República em Gurupi-TO (PRM/Gurupi-TO), que possui competência territorial em 35 municípios do Estado do Tocantins.

À luz da sensibilizada relação de confiabilidade da população com as instituições e do Princípio da Indisponibilidade do Interesse Público, o exercício do poder investigativo da PRM/Gurupi-TO e o adequado tratamento das representações criminais tem relevância regional, aos cidadãos tocantinenses, e nacional, como um elemento da máquina estatal.

Com fundamento em pesquisas documentais nos sistemas oficiais do MPF, pretende-se discorrer as características das notícias-crime dirigidas à Procuradoria, desde inaugurada, e qual o seu resultado prático, conforme as previsões legais. Será discorrido sobre os meios de recebimento, prazos, origens, quantidade e matéria, com a consequente repercussão social após o encerramento das investigações, para o êxito na atividade-fim dessa instituição permanente consagrada pela Carta Magna.

Extraindo-se os resultados da prática ministerial, com o deslinde da questão noticiada que leva ao seu arquivamento, declínio de atribuição ou propositura de ação penal, é possível vislumbrar a efetiva atuação do Ministério Público Federal no contexto social sul-tocantinense, resgatando, ao menos em parte, a sensação de confiança e segurança jurídica pretendida por todo cidadão politicamente ativo. 


\section{MATERIAIS E MÉTODOS}

A pesquisa se enquadra, quanto aos objetivos da pesquisa, na categoria descritiva, que tem como objetivo descrever as características de determinada população ou fenômeno ou estabelecer relações entre variáveis (LAKATOS \& MARCONI, 2001). Com o estudo das notícias criminais na PRM/Gurupi-TO, descrevendo-se as suas características de origem, quantidade, noticiante e matéria, bem como as providências ministeriais, será traçada a repercussão social do ato.

Quanto a sua natureza, pode-se defini-la como quali-quantitativa pois empenhase em quantificar dados e aplicá-los estatisticamente, com considerações a respeito (XIMENES, on-line). À vista disso, trabalhar-se-ão os dados quantitativos de plataformas oficias do MPF, Sistema Único e Sistema Aptus, com fito de proceder à análise subjetiva e fundamentada - daí o seu caráter qualitativo.

Quanto à técnica de coleta de dados, se dará de forma documental e bibliográfica, em fontes primárias, documentos alusivos a arquivos públicos ou particulares de instituições e domicílios, e fontes estatísticas (LAKATOS \& MARCONI, 2001). Os documentos, como leis, decretos, portarias e recomendações, podem ser encontrados em arquivos públicos ou particulares, sites e bibliotecas, assim como a bibliografia, consubstanciada em livros, artigos e meios de informação periódicos.

A pesquisa será realizada no período de janeiro de 2013 a outubro de 2018, a fim de possibilitar um panorama estatístico dos objetos de pesquisa, restrita às notíciascrime de interesse federal e abrangência da comarca de Gurupi, Tocantins.

\section{O PAPEL DO CIDADÃo E dO MINISTÉRIO PÚBLICO FEDERAL ANTE A OCORRÊNCIA DE CRIMES}

Ser cidadão, em um Estado de Direito, pode ser definido como deter e estar consciente de um poder dominante político-social. Etimologicamente, cidadania deriva de civitas (latim), que significa cidade - assim, cidadão é aquele que ocupa determinado status em relação à cidade (GARCIA, 2011, p. 01).

Sob a perspectiva evolutiva social, a cidadania pende ora à visão de nacionalidade (nacional é o "pertencente ao Estado", do alemão, staatsangehörig) e 
identificação cultural com uma nação, ora à participação política na sociedade, exercida no usufruto da liberdade individual de expressar e diligenciar pela satisfação das pretensões que entender de direito para si e especialmente ao bem comum.

Consagrado o Estado Democrático de Direito pela Constituição da República de 1988, dispõe ao art. 5ำ sobre os preceitos dessa condição, consubstanciados em direitos fundamentais individuais e coletivos, acompanhados também de deveres cívicos - tal qual o voto, o cumprimento das leis, o respeito aos direitos sociais de outrem, a educação e proteção de nossos semelhantes, a preservação da natureza e do patrimônio público, a colaboração com as autoridades, etc. (BRASIL,1988).

Nesse contexto, para os nacionais é motivo de grande insatisfação a ocorrência de ilícitos, problema que permeia todas as nações, mas no Brasil toma vultosas proporções, que obrigam o povo a empregar constantes esforços junto ao Estado para o resguardo de seus direitos juridicamente protegidos.

Estatisticamente falando, a quantidade de investigações de crimes de interesse da União, por parte da Polícia Federal, instauradas de ofício ou por representação, aumentou mais do que o dobro em comparação a uma década atrás, havendo 219 operações em curso em 2008, em contraste com o montante de 550 no ano de 2016 (MINISTÉRIO DA SEGURANÇA PÚBLICA, 2016).

Assim, quando qualquer civil ou servidor da administração pública toma conhecimento de um crime, movido pelo dever social e pela lei, comunica-se o fato às autoridades competentes. Com essa conduta, o indivíduo exerce a sua cidadania, não sendo a vítima direta do crime (conquanto seria natural a representação pelo fato), ao escolher agir com ética, entregando o saber às mãos da lei, em lugar de coadunar omissivamente ou juntar-se à injustiça.

Cumprido esse aspecto do papel dos cidadãos, volta-se o olhar às funções do Ministério Público Federal (MPF), como um fiscal da lei e da ordem pública, assegurador dos direitos difusos e individuais assegurados pela CF/88.

Como um órgão federal ao qual recorre o povo para a comunicação de crimes, não pode o Parquet eximir-se de autuar as notícias de fato (NF) que the sobrevêm, ainda que somente para fins de registro - sempre registra-se o texto comunicado, com vinculação às Câmaras de Coordenação e Revisão competentes, e manifesta o seu 
parecer. Fundamentadamente, opta por instaurar procedimento previsto no regimento interno ou pelo simples prosseguimento NF, para a célere apuração da existência de crime e necessidade de colher provas.

Para o devido acolhimento das declarações do povo, são ministrados no âmbito interno do MPF cursos de atendimento ao cidadão, de registro das manifestações no Sistema Único Digital, manuseio de digi-denúncias e também aulas o idioma de libras a servidores designados ou voluntários, para combater as barreiras da comunicação.

Dado o exposto, cada vez mais os brasileiros, integrantes do Estado Democrático de Direito, contribuem para a manutenção e continuidade dessa condição social-estatal, ao exercerem o ato cidadão de noticiar as autoridades competentes, ainda que sigilosamente, colaborando com o estabelecimento da ordem, conforme intentado no Título II da CF/88, que preza pela legalidade na adoção de medidas coativas e investigativas defronte a prática de um ilícito.

\section{AS NOTÍCIAS-CRIME NA PROCURADORIA DA REPÚBLICA EM GURUPI-TO}

A Procuradoria da República no Município de Gurupi-TO foi criada em 07 de fevereiro de 2013, por meio da Portaria PGR/MPF № 40/2013, com intento de aproximar o Ministério Público Federal dos cidadãos e acompanhar a expansão e interiorização da Justiça Federal de 1ํ Grau no Brasil.

Suas atribuições são exercidas nos municípios sujeitos à jurisdição da Vara da Justiça Federal em Gurupi-TO (MPF, on-line): Aliança do Tocantins, Almas, Alvorada, Araguaçu, Arraias, Aurora do Tocantins, Cariri do Tocantins, Chapada da Natividade, Formoso do Araguaia, Gurupi, Jaú do Tocantins, Lavandeira, Natividade, Novo Alegre, Novo Jardim, Palmeirópolis, Peixe, Ponte Alta do Bom Jesus, Porto Alegre do Tocantins, Rio da Conceição, Sandolândia, Santa Rosa do Tocantins, São Salvador do Tocantins, São Valério, Sucupira, Taguatinga, Taipas do Tocantins e Talismã.

De início, há que se esclarecer o método de atuação exercido pelo órgão quanto às notícias de fato é regido pela Portaria PRG/MPF no 566, de 13 de agosto de 2014, regimento interno ao qual se submete a PRM/Gurupi-TO. Conforme incisos de seu art. 41, poderá tramitar no Gabinete de Procurador da República procedimento como a notícia de fato (NF), notícia de fato de instância diversa (como o inquérito policial), 
procedimento preparatório, procedimento investigatório criminal (PIC), entre outros (PROCURADORIA GERAL DA REPÚBLICA, 2014).

Corresponde a NF, segundo inciso I do art. 41, a "qualquer expediente, notícia ou informação submetidos à apreciação do Procurador-Geral da República, conforme as atribuições das respectivas áreas de atuação, que ainda não tenham gerado um feito interno ou externo, podendo ser formulados presencialmente ou não, entendendo-se como tal a entrada de atendimentos, notícias, documentos e representações" (PROCURADORIA GERAL DA REPÚBLICA, 2014).

Destaca-se que a menção de formulação presencial ou não das notícias referese aos vastos meios de comunicação com o cidadão, pessoas jurídicas e servidores da Administração Pública, de outras Procuradorias e do Poder Judiciário, estes últimos geralmente contatando a PRM/Gurupi-TO por meio de ofícios.

Ainda sobre os meios de recebimento de notícias, registram-se manifestações por correio e por contato telefônico, quando há conversação direta com servidor da assessoria jurídica, que registra os fatos em certidão de ligação. É possível, também, comunicar-se pelo e-mail "prto-ascom@mpf.mp.br" disponível no rodapé do site oficial e por representação junto à Ouvidoria. Por fim, desde abril de 2016 está disponível para celulares o SAC MPF, onde às digi-denúncias, assim como no atendimento presencial, pode-se anexar cópias de documentos e mídias como provas do alego.

Conforme incisos I a IV do art. 42 da Portaria PGR no 556/14, o prazo para conclusão de notícias de fato e procedimentos preparatórios é de 30 dias, de 15 dias para as notícias de instância diversa e de 90 dias para PIC, no âmbito interno da PRM (PROCURADORIA GERAL DA REPÚBLICA, 2014).

O estabelecimento dos prazos legais acima discriminados garante o constante manuseio dos procedimentos instaurados, para os quais geralmente se fazem despachos com breves prazos para resposta, como 10 dias corridos, seja oficiando-se uma empresa, órgão ou autarquia para manifestar-se sobre o objeto investigado, seja intimando-se pessoas físicas para, se possível, prestarem informações adicionais ou provas e indicações concretas de seus relatos, presencialmente ou via internet.

Dessa forma, a apuração dos objetos de uma NF depende em grande parte da cooperatividade dos envolvidos com o Parquet Federal, sendo que, no tocante às 
notícias-crime, por vezes é dificultoso contar com a colaboração e localização dos civis, motivo pelo qual a maior parte das NFs com indícios de crime são encaminhadas ao Departamento de Polícia Federal do Tocantins - DPF/TO.

Assim, a Polícia Federal promove o trabalho policial suficiente para o deslinde dos casos, mas também conta com análises da Procuradoria, em pedidos de dilação de prazo, em regra por 90 dias, mediante a verificação da pendência de medidas úteis ou cabíveis à investigação, além da possibilidade do requerimento de diligências complementares, a julgamento do Procurador, em inquéritos findos, para eventual ajuizamento ou complemento comprobatório da ação penal.

\subsection{Autuação de Manifestações}

Recebidas as notícias de fato pelos meios de comunicação, todo procedimento extrajudicial do Ministério Público Federal está vinculado a uma ou mais Câmaras de Coordenação e Revisão (CCRs), a serem indicadas na autuação da NF.

Nesse contexto, cada CCR é responsável por assim revisar a atuação do MPF: $1^{\text {a }}$. direitos sociais e atos administrativos; $2^{a}$. crimes; $3^{\text {a }}$. consumidor e ordem econômica; $4^{a}$. meio ambiente e patrimônio cultural; $5^{\text {a }}$. combate à corrupção; $6^{a}$. indígenas e comunidades tradicionais; $7^{a}$. controle externo da atividade policial e sistema prisional. Tratando-se de NF criminal, são frequentes as $2^{\underline{a}}$, $4^{\underline{a}}$ e $5^{\underline{a}}$ Câmaras.

Assim, no período objeto dessa obra foi registrada na PRM/Gurupi-TO a seguinte quantidade de manifestações extrajudiciais cíveis e criminais, conforme Sistema Aptus do MPF. 
Figura 1. Gráfico da Quantidade de Manifestações Extrajudiciais.

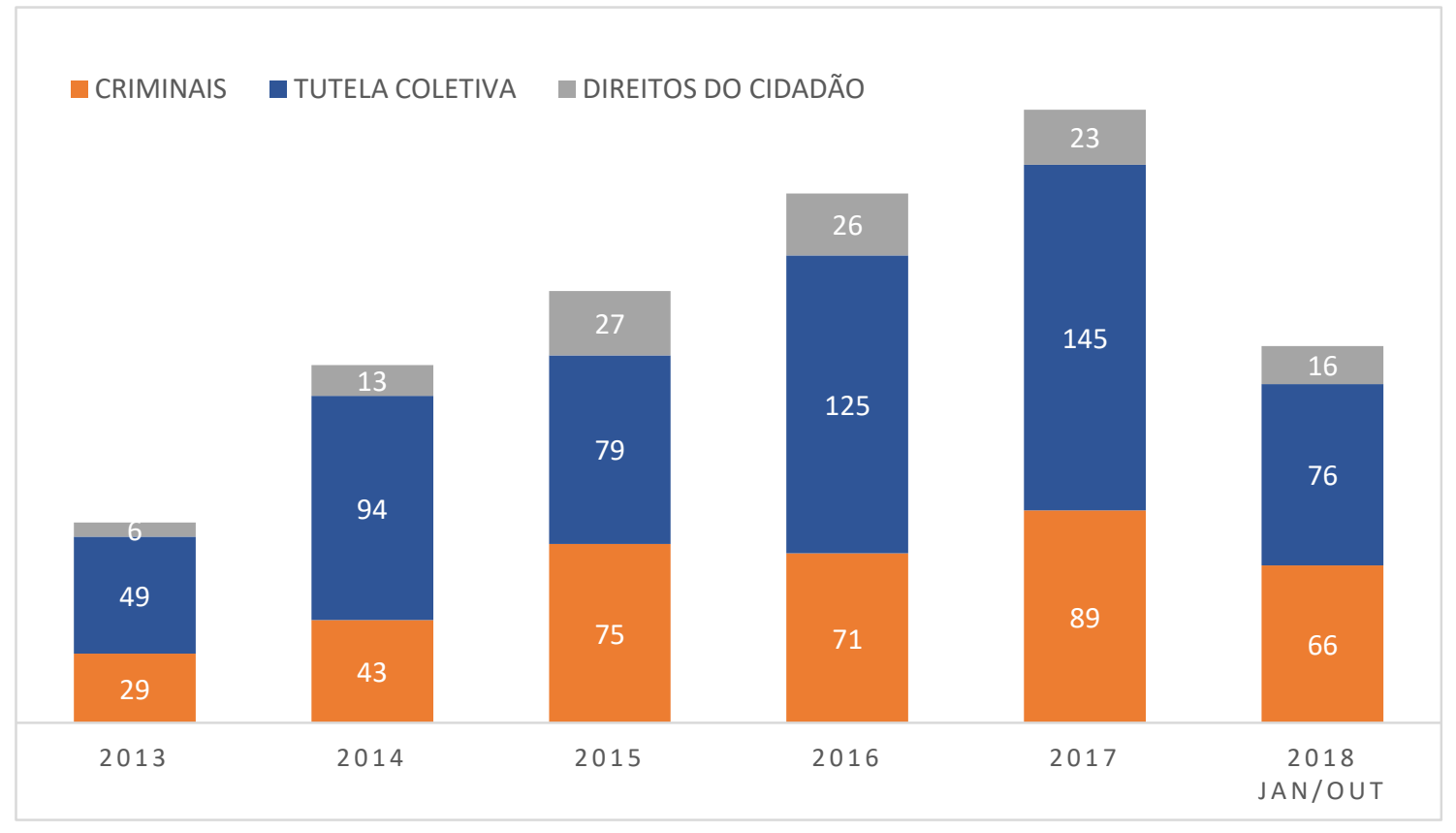

Fonte: Sistema Aptus do MPF, 2018.

De modo geral, do quantitativo depreende-se que a comunicação com a instituição, de 2013 até a atualidade, aumentou gradativamente, de forma positiva. Não se incluem no gráfico inquéritos policiais em curso, pois são judiciais.

Pode-se apontar um conjunto de causas para o enriquecimento da comunicação entre o povo e o Ministério Público: o mero crescimento populacional leva, logicamente, à maior probabilidade de ocorrências, se não acompanhado de proporcional desenvolvimento da qualidade de vida; o incentivo e a adesão de novas formas de diálogo com as instituições públicas, como consequência da busca e desenvolvimento da própria democracia no país; e, principalmente, porque estamos hoje na denominada era da "sociedade da informação".

Viver na sociedade da informação significa que no mundo todo, com auxílio da internet e outras mídias, a informação é difundida mais facilmente e compartilhada de forma cotidiana e natural pelos cidadãos. Disponíveis e públicos todos dados para conhecer o papel do MPF e seus direitos, os brasileiros são mais ativos em tomar atitudes como comunicar o que Ihes desagrada, promover manifestações e campanhas 
virtuais e concretas, além de criarem enquetes, textos e abaixo-assinados para melhor demonstrarem aos representantes do governo as suas vontades.

Dirigir-se ao órgão público, assim, pode ser visto como um meio de expressão revestido de formalidade, diferentemente da internet e manifestações de rua ou culturais, para engatilhar a assistência de uma instituição especializada na instrução e condução à resolução de problemas jurídicos e sociais, com temas específicas.

Quanto à temática das notícias-crime, extraem-se os ulteriores dados.

Figura 2. Gráficos com a Temática das Notícias Crime: 2013 e 2014.
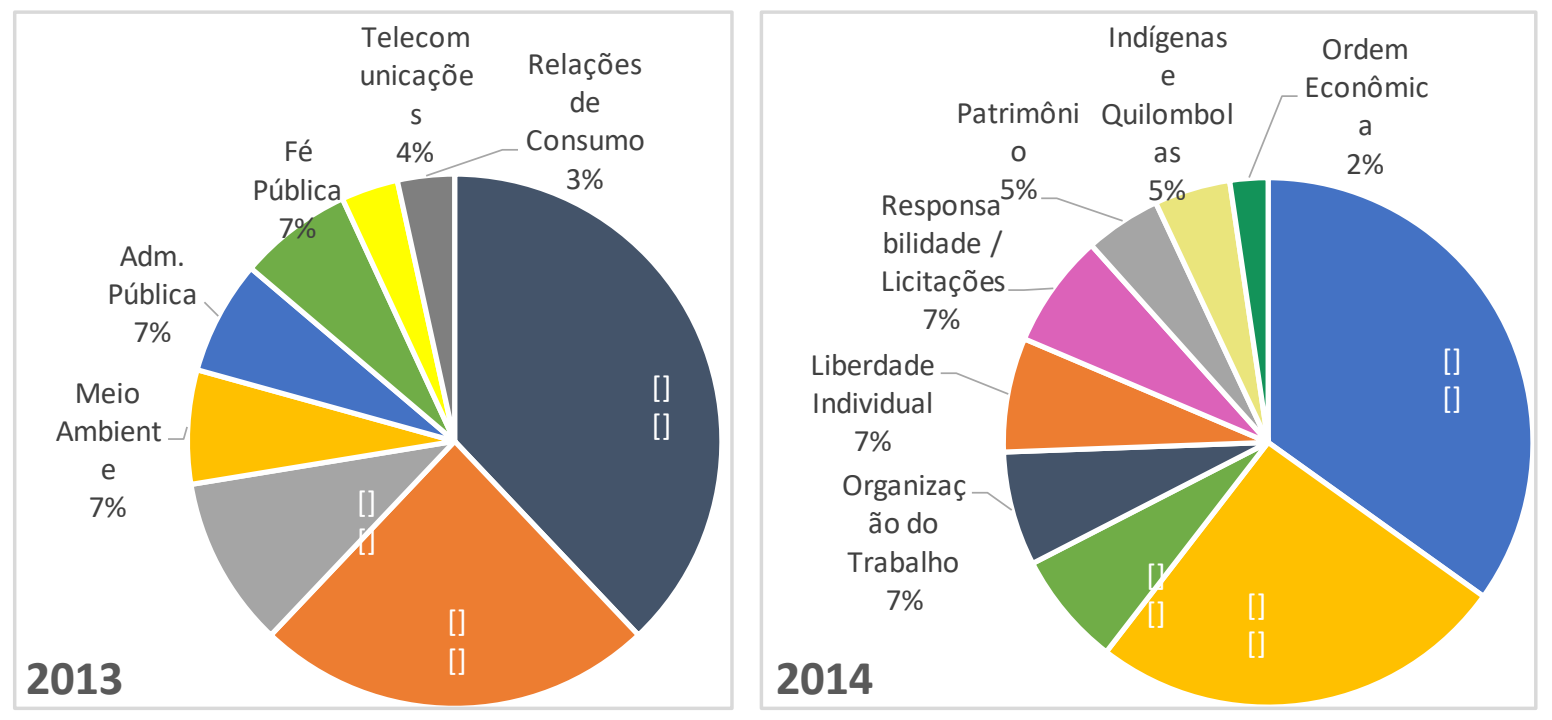

Fonte: Sistema Aptus do MPF, 2018.

Figura 3. Gráficos com a Temática das Notícias-crime: 2015 e 2016.

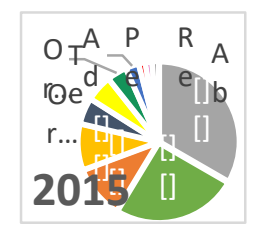

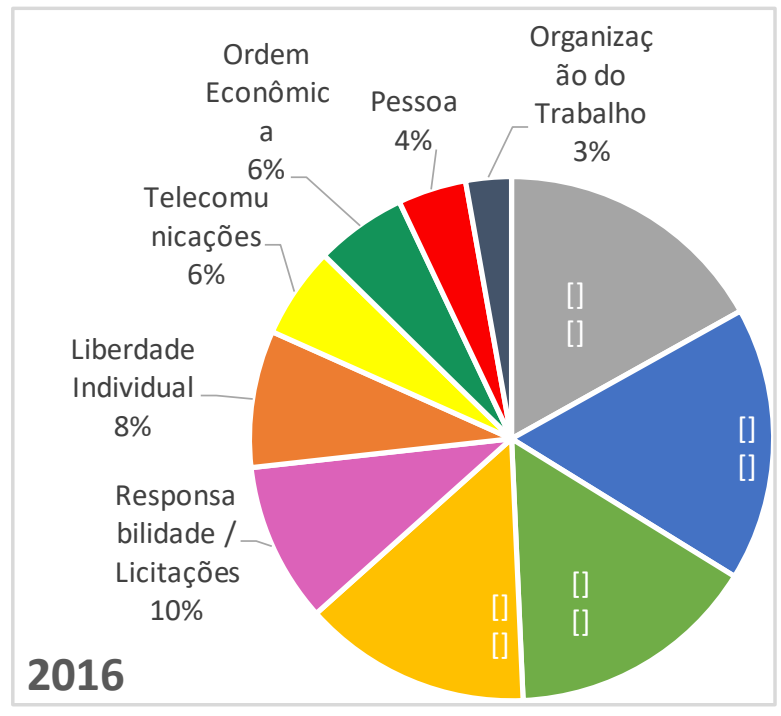

Fonte: Sistema Aptus do MPF, 2018. 
Figura 4. Gráficos com a Temática das Notícias-crime: 2017 e 2018.
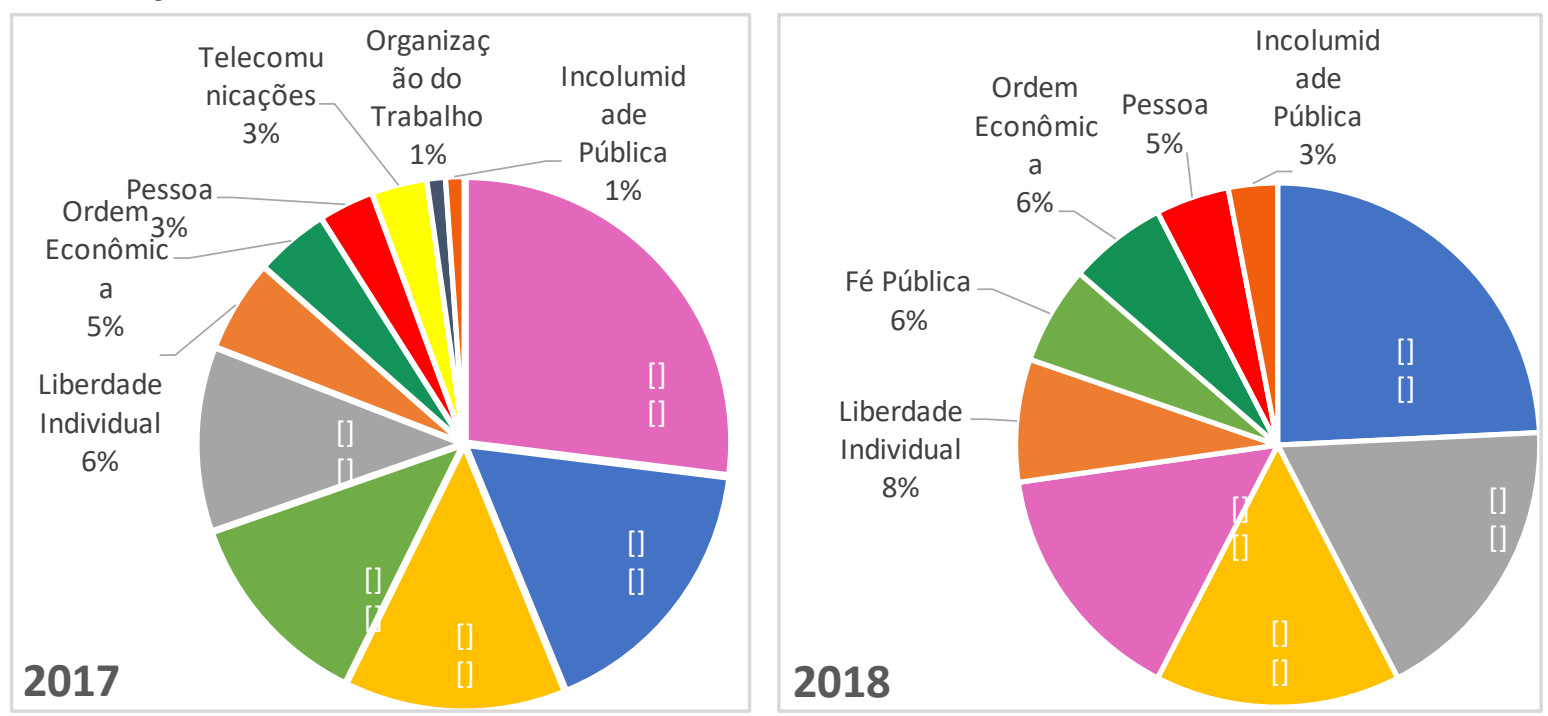

Fonte: Sistema Aptus do MPF, 2018.

Conforme detalhes da pesquisa, destacam-se em recorrência os crimes de responsabilidade do Decreto-Lei 201/67, contra a administração em geral praticada por particular e funcionário público, a apropriação indébita previdenciária, a denunciação caluniosa, a desobediência, a fraude processual, a falsidade ideológica, o uso de moeda e documento falsos, a redução a condição análoga à de escravo e a frustração de direitos trabalhistas.

No ano de 2015, vale ressaltar, sobreveio uma série de notícias de crimes contra a liberdade individual, vida e honra. Trata-se de um grande combate contra o trabalho análogo ao de escravo no Tocantins. O Ministério do Trabalho e Emprego (MTE), em vistorias na zona rural de todo o Estado, autuou em diversas fazendas com essa suporta situação, sempre comunicada à PRM/Gurupi-TO, que geralmente encaminha a NF à Polícia para oitiva dos envolvidos.

O crescimento das manifestações de delitos ambientais, frequentemente associados à exploração ilegal de Áreas de Proteção Permanente (APPs) e terras indígenas da llha do Bananal em Formoso do Araguaia-TO, pode ser relacionado ao progresso das fiscalizações promovidas pelo IBAMA, desde 2014 com a Operação Céu Azul (GOVERNO FEDERAL, 2014) até 2018 com a Operação Shoyo Matopiba (IBAMA, 
2018). As sanções administrativas aplicadas nas redondezas intensificaram a consciência ambiental e a ciência da ilicitude de edificações e lavras.

A partir de 2016 houve significativo aumento de comunicações de delitos praticados por prefeitos, por parte da gestão seguinte, de ofícios do Tribunal de Contas da União e também da população, consoante a crescente politização dos brasileiros e familiarização com o papel do MPF, por meio da midiatização de operações da Polícia Federal e o incentivo, a exemplo, da campanha "10 Medidas Contra a Corrupção" que ganhou divulgação justamente em 2015 (MPF, 2015).

Os delitos contra a fé pública, que perdem em quantidade apenas para crimes de responsabilidade, por vezes se fundam em anúncios de comércio de cédulas falsas em redes sociais, quando não flagradas notas em grandes eventos, como exposições agropecuárias. O uso de documento falso geralmente corresponde à Carteira Nacional de Habilitação, sabido por ofícios do DETRAN. A falsidade ideológica muito se identifica em declarações de atividade rural, via ofícios do INSS ou Justiça Federal.

Quanto à localidade de origem da manifestação, os municípios de onde mais sobrevêm notícias de delitos são Gurupi (234), Formoso do Araguaia (46), Alvorada (18), Peixe (17), Arraias (14), Dianópolis (14), Paranã (12), Araguaçu (10), Natividade (10), Talismã (10) e Taguatinga (10), conforme o levantamento. Levando-se em consideração a quantidade de habitantes, segundo dados de 2017 do IBGE, a proporção entre população e manifestações se visualiza da seguinte forma. 
Figura 5. Gráfico Demonstrativo da Proporção entre a Quantidade de Habitantes e de Manifestações dos Municípios em Análise.

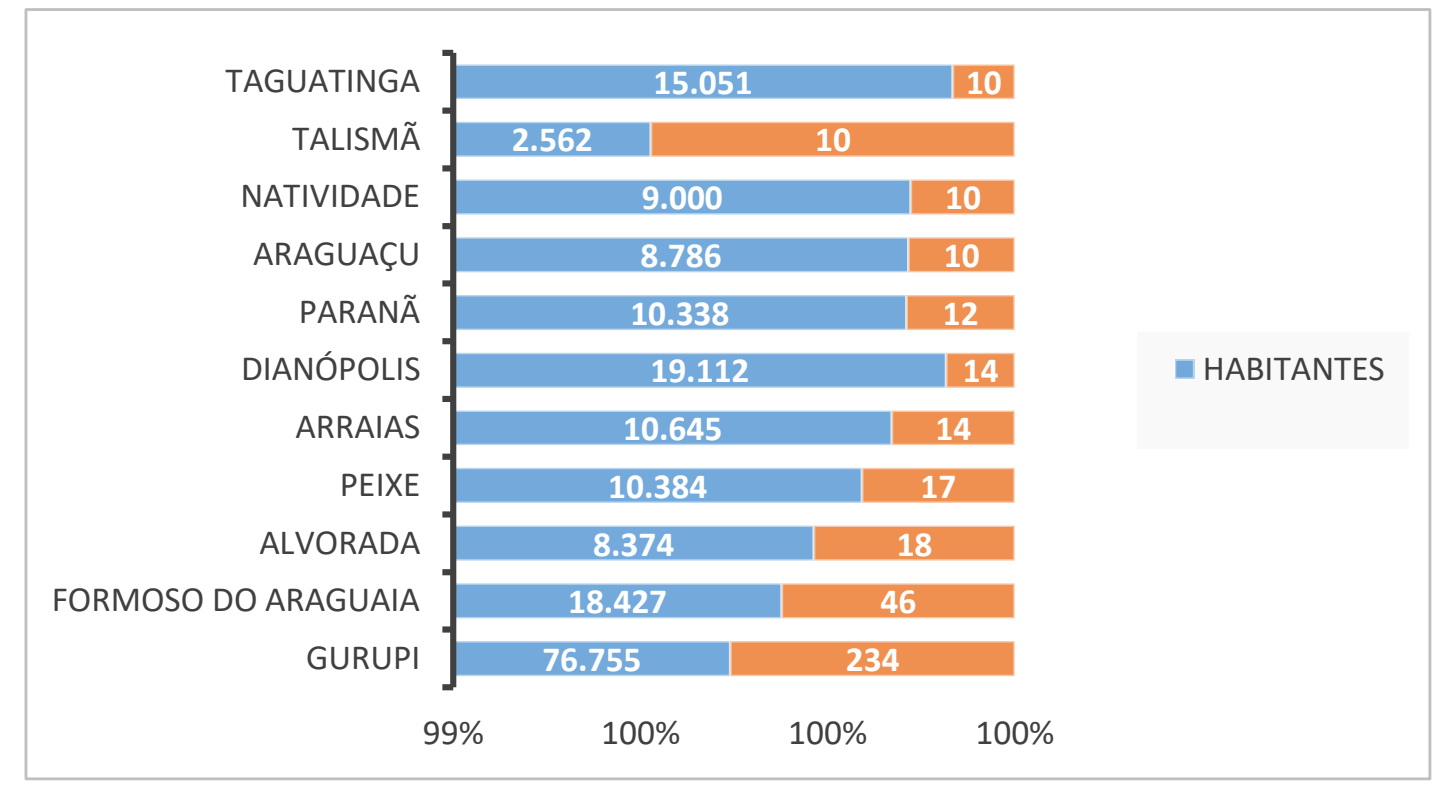

Fontes: Sistema Aptus do MPF, 2018; IBGE, 2017.

Quanto aos sujeitos das manifestações, as procedentes do povo correspondem a aproximadamente $27 \%$ das notícias criminais, sendo $86 \%$ não sigilosas e $14 \%$ sob a roupagem da sigilosidade. Os demais noticiantes representam, em ordem crescente de quantidade, o Juízo Federal de Gurupi/TO, o IBAMA, o Ministério Público do Trabalho e o MTE, o Ministério Público Estadual, as Prefeituras, as Câmaras de Coordenação e Revisão, o Instituto Chico Mendes de Conservação da Biodiversidade (ICMBio), a Agência Nacional de Telecomunicações (ANATEL), os Tribunais de Contas, o Departamento Nacional de Preservação Mineral (DNPM), a Empresa Brasileira de Correios e Telégrafos (EBCT), a Fundação Nacional do Índio (FUNAI), os Tribunais de Justiça e o Ministério da Agricultura, Pecuária e Abastecimento (MAPA).

É evidente o benefício trazido pela faculdade de revestir-se do anonimato perante os envolvidos no delito comunicado, visíveis os dados do manifestante apenas pelos próprios servidores da assessoria administrativa ou, sendo também sigilosa a matéria do suposto crime, somente por servidores designados para o seu manuseio, por portaria expedida pelo Procurador da República. 


\subsection{Providências e Resultados}

$\mathrm{Na}$ sequência, se analisa a primeira providência, a dedução de medida administrativa ou jurídica cabível do teor das manifestações recebidas. Sendo primordial a verificação de competência para os atos da Procuradoria, a atenção inicial é para a hipótese de declínio de atribuição, conforme art. 43, V, do Regime Interno (PROCURADORIA GERAL DA REPÚBLICA, 2014), podendo a apuração ser desmembrada se preciso.

Nessa etapa, estuda-se o local de consumação do suposto crime, para remessa à Procuradoria adequada, por vezes em estado federativo diverso ao Tocantins, nos casos, por exemplo, de estelionato consumado em lugar distinto ao da vítima residente em município tocantinense ou falsificação de $\mathrm{CNH}$ realizada no local onde o agente responsável apenas pelo uso de documento falso a comprou.

A matéria do crime deve ser também sobepesada, por vezes sendo o caso de envio da notícia-crime ao Ministério Público Estadual (MPE), por ausência de interesse federal nos termos dos incisos do art. 109 da Constituição Federal, tais como as manifestações sobre crimes ambientais às margens de rio estadual. Não sendo o caso de interesse federal, toda notícia que verse sobre crime de ação pública incondicionada é encaminhado à autoridade estadual competente.

Confirmada a competência da PRM/Gurupi-TO para investigar o feito, se checa a possibilidade de prosseguimento do apuratório, se presentes os indícios mínimos de prova ou existência do crime. Não havendo meios de se obter elementos da materialidade ou autoria, promove-se o arquivamento, devidamente fundamentado, pendente de homologação ou comunicação à respectiva CCR e o envio de cópia da peça ao representante, para que entenda os motivos da medida, comunicando à autoridade correta em caso de interesse particular ou, discordando, apresente recurso por escrito no prazo de 10 dias, conforme art. 58, $\S \S 1^{\circ}$ e $2^{\circ}$, do Regimento Interno.

Preenchidos os requisitos, dá-se prosseguimento ao feito, autuando-se como Notícia de Fato, Procedimento Investigativo Criminal ou Procedimento Preparatório, propondo ação penal caso suficiente o conjunto comprobatório ou determinando remessa dos autos ao Departamento de Polícia Federal (DPF/TO) conforme as peculiaridades do delito a ser investigado. 
Dessa feita, vislumbram-se as medidas a seguir por parte da Procuradoria, em levantamento da primeira e última providência quanto às NFs criminais.

Figura 6. Gráficos com a Primeira e a Última Providência da PRM/Gurupi-TO perante as NFs Criminais.

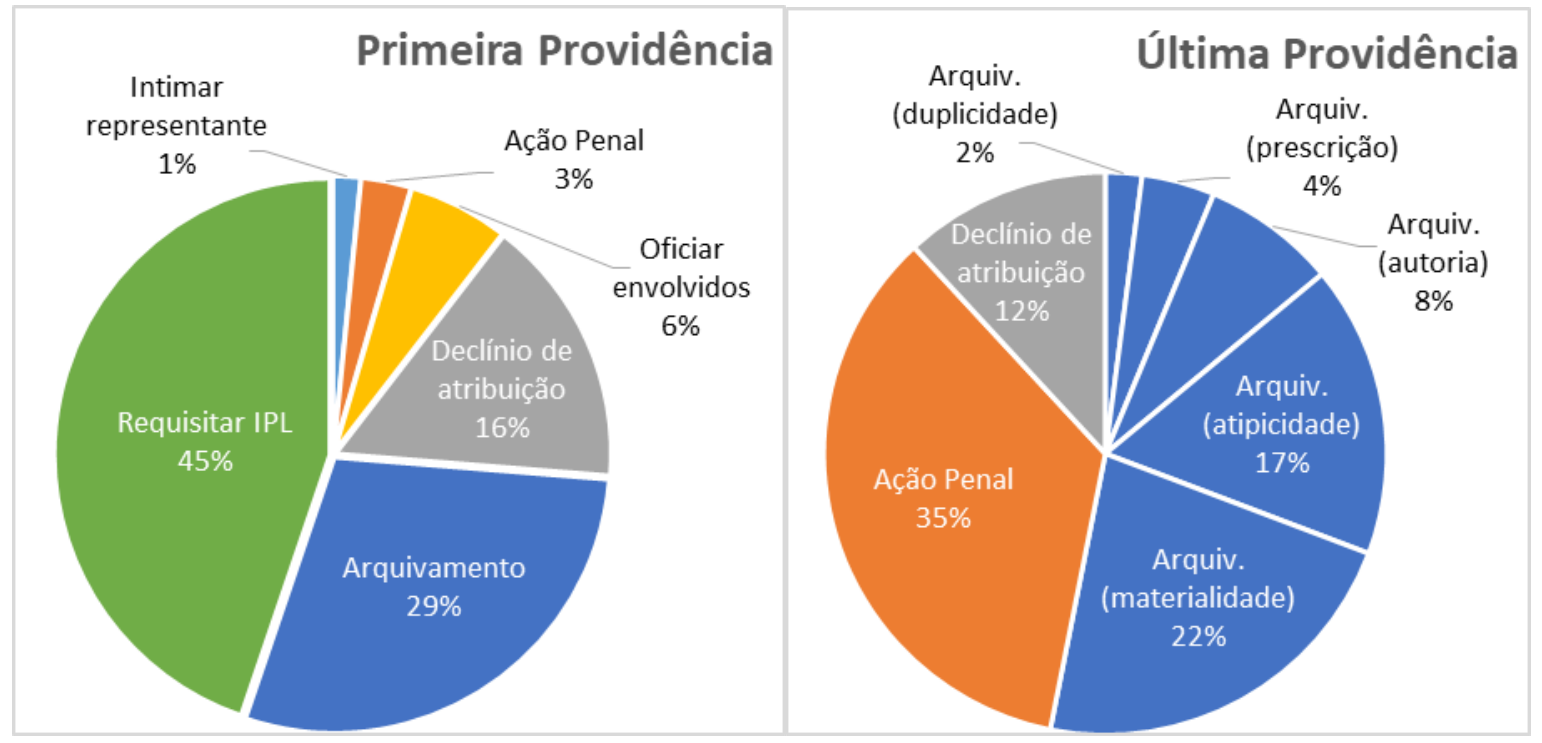

Fonte: Sistema Aptus do MPF, 2018.

Em pesquisa pormenorizada da matéria das ações penais, que no total foram 61 ajuizadas no período objeto, verifica-se que são mais recorrentes as relativos, na respectiva ordem, à fé pública, meio ambiente, responsabilidade / licitações, liberdade individual, administração pública e patrimônio. Por outro lado, o vislumbre da ausência de crime, com o consequente arquivamento, é também uma conclusão e uma resposta satisfatória, pois desvendou-se o caso trazido à baila pelo noticiante.

\section{CONSIDERAÇOES FINAIS}

O desenvolvimento do presente estudo possibilitou uma análise de como a comunicação de uma conduta ilícita ao Ministério Público Federal, seja dada por pessoa física e/ou autoridades públicas, podem levar a adoção de medidas que impactam de forma direta o meio social.

$\mathrm{Na}$ fase de investigação, o local do suposto crime é vistoriado e os envolvidos são acionados para que prestem informações, podendo o próprio representante contribuir a qualquer tempo com a apuração do fato. Caso a notícia seja indeferida ou 
arquivada, não deixa o manifestante de ser cientificado das justificativas, sendo-lhe oportunizada voz em eventual discordância. Encerradas as diligências, a conclusão pela existência de crime, pelas provas colacionadas, leva à propositura de ação penal.

Em época de descrença generalizada nas instituições públicas, o noticiante se dirige ao Ministério Público, certamente, com anseio de ver cumpridas e satisfeitas as suas pretensões de justiça. Evidente, assim, a importância do amplo acesso ao ente ministerial para comunicados de quaisquer gênero, pelos meios demonstrados.

Além disso, a pesquisa de campo na Procuradoria da República em Gurupi-TO obteve dados consistentes e atualizados sobre as quantidades, meios de recebimento, titulares, matérias e conclusões das notícias de fato na referida. Houve um estudo do papel do cidadão e do Ministério Público Federal diante da ocorrência de crimes, que remeteu às ideias de cidadania, ética e deveres cívicos, assim como de instituição permanente e fiscal do Estado Democrático de Direito.

Após breves considerações sobre a criação da PRM/Gurupi-TO em 2013 e os procedimentos que nela tramitam, as pesquisas no Sistema Aptus demonstraram a quantidade e matéria das notícias-crime, interpretadas conforme a quantidade de habitantes dos municípios, possibilitando uma análise contextual social e jurídica dos resultados, ao passo que os dados do Sistema Único Digital revelaram os sujeitos e origens das manifestações para, por fim, expor os iniciais e derradeiros contatos da Procuradoria com a notícia de fato criminal.

De posse desses dados, se poderia ir mais além na pesquisa dos impactos sociais, adentrando-se no mérito da procedência ou não das ações penais citadas, bem como da aplicação de questionários para pesquisa de satisfação da população tocantinense acerca das instituições públicas e do MPF em específico, levando à conclusão mais acurada da relação da população tocantinense com o próprio direito. Por fim, tal itinerário caberia igualmente às notícias cíveis e inquéritos policiais.

Os resultados percebidos, em contraste ao verificado fato de que a confiança da população para com as instituições públicas é a menor da última década, levam à dedução de que o robustecimento do diálogo com as mesmas, aparentemente paradoxal, nada tem de controverso. Ora, não é necessário que se ponha profunda fé em um sistema para ceder, em um primeiro momento, aos seus procedimentos, uma 
vez evidente a boa-fé do indivíduo que, antes de qualquer atitude extraordinária, segue o "protocolo social" esperado e constitucionalmente previsto.

Apesar da instável crença na efetividade da medida de "reclamar" à órgãos públicos, de onde se ouvem tantas notícias de carência de servidores, recursos e até corrupção, o cidadão opta, ainda assim, por usufruir de toda ferramenta de poder ao seu alcance, nesses tempos de ativismo político, mesmo porque assim fica registrada formalmente e preservada no sistema toda a sua colaboração.

São detectados pelos civis e empresas as informações de casos que deram certo, as medidas exitosas do povo junto às autoridades e instituições, a comunicação das entidades com os interessados via diversas ferramentas (e-mail e telefone, não somente postal), assim como as reportagens sobre lutas judiciais, sociais e culturais recorrentes na televisão, rádio e portais oficiais de notícias, onde a temática jurídica aparece com frequência.

Da apreciação de parte da atuação extrajudicial criminal do Ministério Público Federal no sul tocantinense, pode-se considerá-la produtiva pois, graças à comunicação do cidadão e servidores da administração pública com a Procuradoria, já foram apuradas cerca de 373 notícias-crime.

A efetiva propositura de aproximadamente 61 ações penais foi possível justamente devido ao canal de diálogo do Parquet. Portanto, evidente o reflexo positivo da atuação ministerial na região de Gurupi-TO, colaborando com a cidadania, bemestar social e a sensação de segurança jurídica que é de interesse público.

\section{REFERÊNCIAS}

BRASIL. Código Penal. Decreto-Lei oㅡ 2.848, de 7 de dezembro de 1940. Disponível em: <www.planalto.gov.br/ccivil_03/decreto-lei/Del2848compilado.htm>. Acesso em: 05 set. 2018.

. Constituição da República Federativa do Brasil de 1988. Disponível em: <www.planalto.gov.br/ccivil_03/constituicao/constituicaocompilado.htm>. Acesso em: 05 set. 2018.

GARCIA, Emerson. Cidadania e Estado de Direito: breves reflexões sobre o caso brasileiro. Rio de Janeiro: Emerj, 2011. Disponível em: <www.emerj.tjrj.jus.br/ revistaemerj_online/edicoes/revista53/Revista53_69.pdf>. Acesso em: 14 ago. 2018. 
GOVERNO FEDERAL. Ibama realiza Operação Céu Azul contra o desmatamento. Disponível em: <www.brasil.gov.br/noticias/meio-ambiente/2014/10/ ibama-realizaoperacao-ceu-azul-contra-o-desmatamento>. Acesso em: 01 nov. 2018.

HERÉDIA, Thais. $62 \%$ dos brasileiros não acreditam nas instituições do país, diz pesquisa. Rio de Janeiro: Globo News, 2017. Disponível em: <http://g1.globo.com/economia/blog/thais-heredia/post/62-dos-brasileiros-naoacreditam-nas-instituicoes-do-pais-diz-pesquisa.html>. Acesso em: 25 ago. 2018.

IBAMA. Operação Shoyo Matopiba: Ibama aplica $\mathrm{R} \$ 105,7$ milhões em multas por plantio ilegal de grãos em áreas embargadas no Cerrado. Disponível em: $<$ www.ibama.gov.br/noticias/436-2018/1467-operacao-shoyo-matopiba-ibama-aplica-r105-7-milhoes-em-multas-por-plantio-ilegal-de-graos-em-areas-embargadas-nocerrado>. Acesso em: 01 nov. 2018.

IBGE - INSTITUTO BRASILEIRO DE GEOGRAFIA E ESTATÍSTICA. Censo Demográfico, 2017. Disponível em: <www.ibge.gov.br>. Acesso em: 15 set. 2018.

JORDÃO, Claudia. Edelman Trust Barometer 2017 aponta crise generalizada nas instituições no Brasil. [s.l.]: Edelman, 2017. Disponível em: <http:// edelman.com.br/propriedades/trust-barometer-2017/>. Acesso em: 25 ago. 2018.

LAKATOS, E. M.; MARCONI, M. A. Fundamentos da Metodologia Científica. 5 ed. São Paulo: Atlas, 2003.

MINISTÉRIO PÚBLICO FEDERAL. Câmaras de Coordenação e Revisão do MPF. Disponível em: <www.mpf.mp.br/conheca-o-mpf/atuacao/camaras-de-coordenacao-erevisao>. Acesso em: 15 set. 2018.

. Gurupi. Disponível em: <www.mpf.mp.br/to/municipios/procuradoria-darepublica-no-municipio-de-gurupi>. Acesso em: 15 set. 2018.

. Portal da Transparência. Disponível em:

<http://apps.mpf.mp.br/aptusmpf/portal>. Acesso em: 19 set. 2018.

. Sistema Único Digital. Disponível em: <https://portal.mpf.mp.br/unico>. Acesso em: 25 out 2018.

POLÍCIA FEDERAL. Estatística de Operações. Disponível em: <www.pf.gov.br/imprensa/estatistica/operacoes>. Acesso em: 20 out. 2018.

PROCURADORIA-GERAL DA REPÚBLICA. Portaria PGR/MPF no 556, de 13 de agosto de 2014. Disponível em: <www.mpf.mp.br/atuacao-tematica/sci/normas-elegislacao/portarias-pgr/docs_portarias/portaria-pgr-no-556-2014>. Acesso em: 20 out. 2018. 
XIMENES, Julia Maurmann. Levantamento de Dados na Pesquisa em Direito - A Técnica da Análise de Conteúdo. Disponível em: <www.idp.edu.br/com ponent/ docman/doc_details/145-levantamento-dedados-na-pesquisa-em-direito--a-tecnica-daanalise-de-conteudo>. Acesso em: 18 ago. 2018. 